\title{
Employing waterborne autonomous vehicles for museum visits: a case study in Amsterdam
}

\author{
Helena Hang Rong ${ }^{1,2^{*}}\left(\mathbb{D}\right.$, Wei Tu ${ }^{1,3}$, Fábio Duarte ${ }^{1,4}$ and Carlo Ratti ${ }^{1}$
}

\begin{abstract}
Amsterdam is a culturally rich city attracting millions of tourists. Popular activities in Amsterdam consist of museum visits and boat tours. By strategically combining them, this paper presents an innovative approach using waterborne autonomous vehicles (WAVs) to improve the museum visitation in Amsterdam. Multi-source urban data including I Amsterdam card data and Instagram hashtags are used to reveal museum characteristics such as offline and online popularity of museums and visitation patterns. A multi-objective model is proposed to optimize WAV routes by considering museum characteristics and travel experiences. An experiment in the Amsterdam Central area was conducted to evaluate the viability of employing WAVs. By comparing WAVs with land transportation, the results demonstrate that WAVs can enhance travel experience to cultural destinations. The presented innovative WAVs can be extended to a larger variety of points of interest in cities. These findings provide useful insights on embracing artificial intelligence in urban tourism.
\end{abstract}

Keywords: Waterborne autonomous vehicle, Genetic optimization, Route recommendation, Museum, GIS

\section{Introduction}

Museums are regarded as potential drivers for attraction in urban tourism [1] and urban economy [2]. As a culturally rich city, Amsterdam has more than 70 museums within its inner-city ring, attracting millions of tourists each year [3]. However, visitation distribution among these museums is tremendously uneven, with $50 \%$ of total visitors distributed among the top five museums. Currently, modes of transportation to these destinations are limited to ground transportation. Meanwhile, as a major port city, Amsterdam is defined by a network of canals totaling hundreds of kilometers [4]. The canal has historically been used for a variety of functions, including transporting people and delivering goods. However, with the inner ring preserved as part of UNESCO World

\footnotetext{
* Correspondence: hrong@mit.edu

${ }^{1}$ Senseable City Lab, Massachusetts Institute of Technology, MIT 9-216, 77

Massachusetts Avenue, Cambridge, MA 02139, USA

${ }^{2}$ Graduate School of Architecture, Planning and Preservation at Columbia

University in the City of New York, New York City, NY 10027, USA

Full list of author information is available at the end of the article
}

Heritage, its contemporary use has been reduced to a single function: cruise for tourism, one of the two most popular touristic activities in Amsterdam. As a result, increasing tourism leads to conditions of unbearable urban congestion in the canals, especially during summer. These combined conditions in Amsterdam present both an urban problem and a planning opportunity. One goal of this study is to investigate the possibility and potentials of improving museum tourism by leveraging the proximity of museums to canals and the popularity of boat tour activities in Amsterdam.

Meanwhile, artificial intelligence (AI) is changing contemporary cities by introducing disruptive technologies and smart city operations [5]. AI is incorporated into urban solutions as tools to solve urban issues and bring more efficiency [6-9]. Autonomous vehicles (AV) are imagined to drastically change the mobility landscape in cities. While most researches thus far have focused on AV travels for daily commutes [10,11], few have examined its effect on tourism. There is a surge of interest from both 
academia and the practical world to approach urban issues in the context of an autonomous future $[12,13]$.

Although land AV technologies have been widely researched, little attention has been given to waterborne autonomous vehicles (WAVs). In 2016, Massachusetts Institute of Technology and Amsterdam Metropolitan Solutions Institute collaborated to introduce autonomous "roboats" to solve complex urban issues for Amsterdam. Figure 1 shows the conceptual design of the roboat module, which can combine to form floating bridges and stages, collect waste, deliver goods, and transport people. By introducing WAVs in Amsterdam's canals, we investigate how AI can be used to improve urban tourism while breaking technological frontiers in the branch of AV.

Reclaiming the canal as an intercity infrastructure with potentials to transport people, we present a novel approach to integrate big data analytics and innovative WAVs to improve museum visitation experience in Amsterdam. Using historical museum data and social media data, we extract online and offline popularity indices for each museum, and preferences and travel patterns of visitors. We propose a multi-objective model to find optimal WAV-based travel routes to museums. The genetic optimization heuristics is used to solve the presented problem. The experiment in Amsterdam's central area demonstrates that, by taking advantage of canal networks, the WAV-based museum tour outperforms land transportation with better travel experiences and comparable efficiency, confirming the viability of embracing WAVs in Amsterdam's museum tourism industry. This study contributes to the nascent discussion of AVs' effects on tourism by combining innovative WAVs and selected factors influencing tourism visitation to cultural venues, specifically museums.
The remainder of this paper is as follows: Section 2 reviews related literature; Section 3 introduces the study area and datasets; Section 4 presents the proposed multi-objective framework to find optimal WAV routes; Section 5 reports the results and compares them with land transportation; Section 6 discusses practical issues and concludes this study and speculates on future work.

\section{Literature review}

\subsection{Data-driven tourism management}

\subsubsection{Tourism and social media}

The developments of information communication technologies and social media have great influences on tourism management [14]. Numerous researches studied the correlation between the popularity of tourist destination and their online presence on social networks, such as Flickr, Facebook, Twitter, and Instagram (Larsen et al. [15-17]). Vu et al. [18] crawled pictures from Flickr and investigated Hong Kong's inbound tourism, including area of interest, tourist movement patterns, and tourist activities patterns, which helps future policy-making. Using geo-tagged photos in Italian cities, Giglio et al. [19] revealed incomes for areas of interest. These studies show big data analytics can create a predictive model to formulate tourism scenarios [20].

Social media has become increasingly important for museums to attract young people, directly communicate with users and build long-term relationships with visitors [21-23]. For example, Dutch museums are curating online presence on Twitter, LinkedIn, Instagram and Facebook to promote their offline businesses [3]. In this study, we considered social media exposure to be one of the weighted factors in WAV route recommendation.

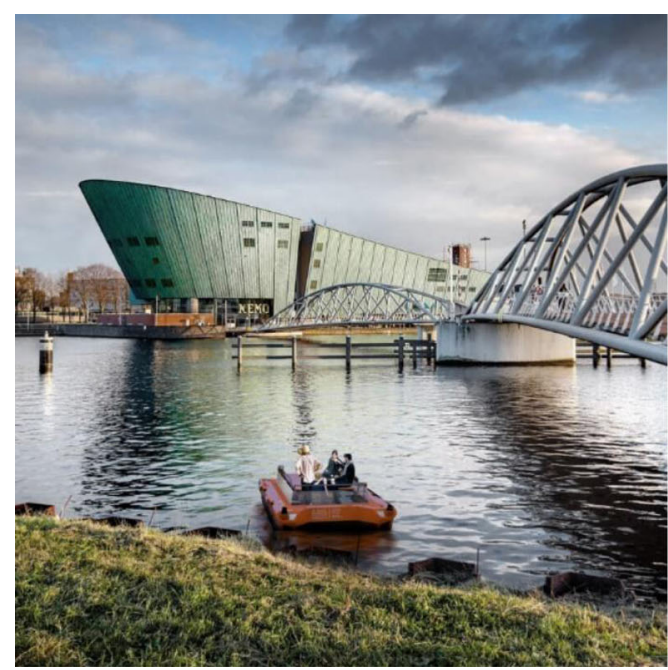

Fig. 1 Proposed design of WAVs (Senseable City Laboratory, MIT)

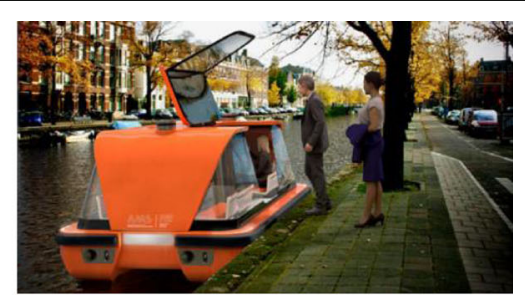

Urban Interface of Roboat

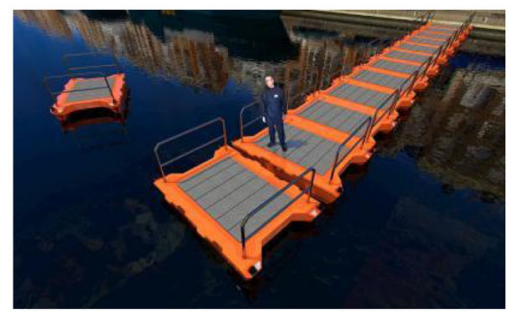

WAV modular combination 
We scraped Instagram hashtags for Amsterdam museums to assess online popularity.

\subsubsection{Tourist package}

Tourist package has been recognized as an effective tool to attract tourists. Van der Werff et al. [24] developed an econometric count model to assess the museum pass's impact on tourism using Dutch museum pass data. Different characteristics of museum visitors with and without museum pass were considered as influential drivers for cultural participation, such as gender, age, region, household income, and education. Their findings show that the museum pass has a positive and significant effect on the museum visits, with consideration of differences in individual background characteristics.

The success of the Dutch museum pass attributes to the high population density of museums within a reasonable travel distance. This renders the site of Amsterdam a suitable testing ground for experimenting with alternative modes of maritime transport that would enhance connecting multiple museums through WAVbased tour and foster collaborations between them for higher economic benefits. The scope of this research does not speculate the economic benefits nor the amount of increase in visitation as result of the proposed use of WAVs. However, based on these findings and prior research on tourist packages, we design optimal WAV-based routes by considering visitation sequences.

\subsection{Autonomy and urban tourism}

Autonomous vehicles have the potential to revolutionize travel behavior and urban development by reducing traffic congestion and improving network capacity and travel efficiency $[25,26]$. There has been growing interest in speculating how AVs can operate in urban areas and what impacts they have on urban mobility [27]. Milakis et al. [28, 29] forecasted the percentage of AVs in vehicle fleets to be less than $11 \%$ in year 2030 and between $7 \%$ and $61 \%$ in year 2050 , expecting coexistence of traditional vehicles and AVs in the next few decades.

On the other hand, a rich body of literature investigates the effects of AVs on urban mobility landscape $[11,12,15]$. They demonstrate that the emergence and acceptance of AVs could lead to more efficient and intelligent transportation [30]. Across all applications of AVs, autonomous taxis have received the highest attention, due to expected rapid gains in early market share (Greenblatt and Saxena [31]). Existing social interactions, notion of accommodation and urban spatial relations are bound to change.

While a large amount of research studies the effect of autonomous vehicular travels for daily commutes [10, 11], few researches study the potential future widespread implications of AVs for the tourism industry. Recently,
Cohen and Hopkins [32] seek to break new ground in the tourism domain by considering potential implications of connected autonomous vehicles with a focus on urban mobility. They argued that new urban tourism destinations which may be hard to access previously could emerge as popular points of interest due to newfound transport connectivity.

In the case of the Netherlands, the country places first on the list of cities well-prepared for the future of AVs according to the automated vehicles readiness [33]. Against this background, introducing autonomous boat infrastructure in the Netherlands can be assumed to be high. Amsterdam specifically is well-positioned to take advantage of on-demand waterborne autonomous technologies with its robust networks of canals. Therefore, we can assume that at least in the early-on adoption process of AVs, experiencing a trip with the WAV through the touristic landscape will be an attraction in its own right.

\subsection{Route optimization}

Routing for vehicles have long been studied in the domain of transportation and urban operations [34]. The goal is to find efficient paths for transporting items through a complex network. Generally, the routing problem is modeled as the shortest path problem (SSP), the traveling salesman problem (TSP), or vehicle routing problem (VRP). SSP finds the best route from an origin to a destination [35]. The route quality is usually indicated by travel distance, time, congestion, or experience. Different from SSP, TSP finds the shortest route visiting multiple places, rather than having one destination [34]. The TSP route should eventually return to the departure point. When more than one vehicle is considered, VRP is used to find the optimal routes traversing a set of locations for a fleet of vehicles [7, 8]. Different from TSP, in VRP, multiple vehicles depart from depots or warehouses and cooperate to deliver or pick-up goods [36]. All three types of models have been widely applied in many smart city applications, such as pedestrian navigation in complex urban environment [37], tourist route recommendation [38], taxicab operations [39], urban logistics $[7,8]$, etc.

Route problems are difficult to solve for the inherent characteristic. Small size SSP can be efficiently solved with exact algorithm, such as the Dijskra and the brunch-andcut. For example, the A-Star can solve the SSP in a transportation network with thousands of nodes in a minute. Regarding TSP and VRP, they can be solved with the exact and the heuristics algorithm. As TSP and VRP belong to the combination problem, it is hard to use them to solve large scale problems in a reasonable time $[7,8]$. Heuristic algorithms are effective to find local optimal routes, such as the insertion heuristics, local search, simulated annealing, ant colony optimization, and genetic algorithm. In this 
study, we model the design of WAV routes as a variant of the routing problem and solved it with the genetic algorithm.

\section{Study area and data sets}

The Dutch capital of Amsterdam has more than $100 \mathrm{~km}$ of canals, most of which are navigable by boats. Famed for its culturally rich history and advanced development of the arts, Amsterdam has the highest concentration of museums in the world. Gemeente Amsterdam maps 164 museums in the city and surrounding areas, 48 of which are members of the Official Museums of Amsterdam (OAM). More than $90 \%$ of them are located either along the edge of the canal, or within less than $200 \mathrm{~m}$ of walking distance to the canal. Figure 2 displays the network of canals and museums in Amsterdam's city center. These geographic and cultural contexts highlight the advantages of employing WAVs to museum tourism. In our study, we only select museums in the Central area to investigate the WAV-based museum tour.

Three datasets are used to design the optimal museum tour routes using WAVs. The first is the geographic canal data. The connected canals are extracted to represent the travelable area for WAVs. Central lines of the canals are connected to build a water network for further route optimization. The second dataset is from the Amsterdam Museum Monitor Report 2016, which summarized the museum tourist information. The annual visitations of museums are digitized to denote the offline popularity. Considering the sequential museum visitation in a day, the transition between museums are learned to represent travel patterns to museums in one route. The third dataset is scraped Instagram data of all the museums in Amsterdam that denotes the museum's online presence and popularity. Details of data processing are described in the following section.

\section{Methodology}

We present an innovative optimization framework integrating big data analytics to design optimal WAV-based museum tour routes. Figure 3 displays the workflow. Combining canal networks and museum locations, the travelable graph is firstly built for WAV. Characteristics of museums are harvested from [3] and Instagram to assess offline and online popularity of museums and current travel patterns of tourists. A multi-objective model is developed by considering online and offline popularity, travel patterns, and WAV travel cost. The model is solved by genetic optimization to find the optimal travel routes using WAVs. Finally, the connected museums and WAV-based tour routes are reported and analyzed.

\subsection{Assessing the characteristics of museums 4.1.1 Museum visitation}

The Netherlands Museum Association was established in 1926 to promote Dutch cultural heritage and to focus on advocacy and professional development of its members. In 2003, the Museumkaart foundation was integrated into the Netherlands Museum Association. The Museumkaart (museum card), targeting domestic travelers and local residents, is an annual membership card which gives unlimited free entry into over 400 museums in the Netherlands, 40 of which are in Amsterdam. The program has been running since 1981 and has around 1.35 million cardholders.

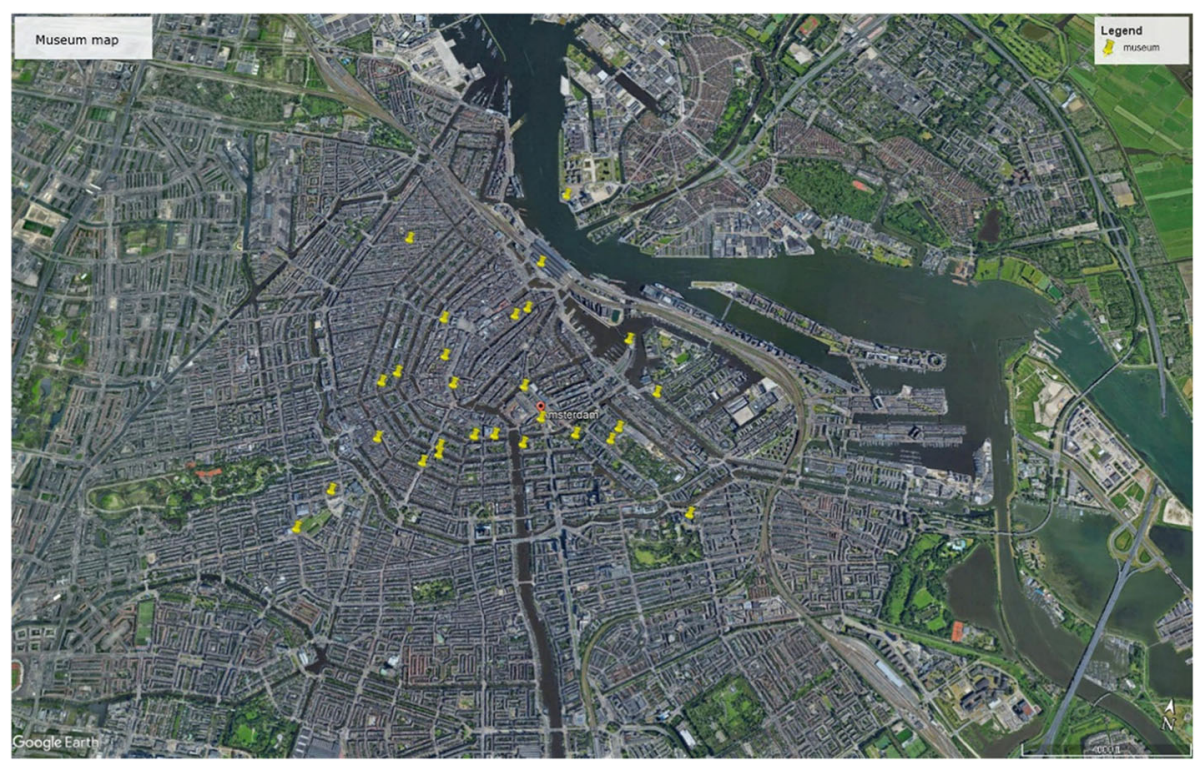

Fig. 2 The museums and canals in Amsterdam. @google map 


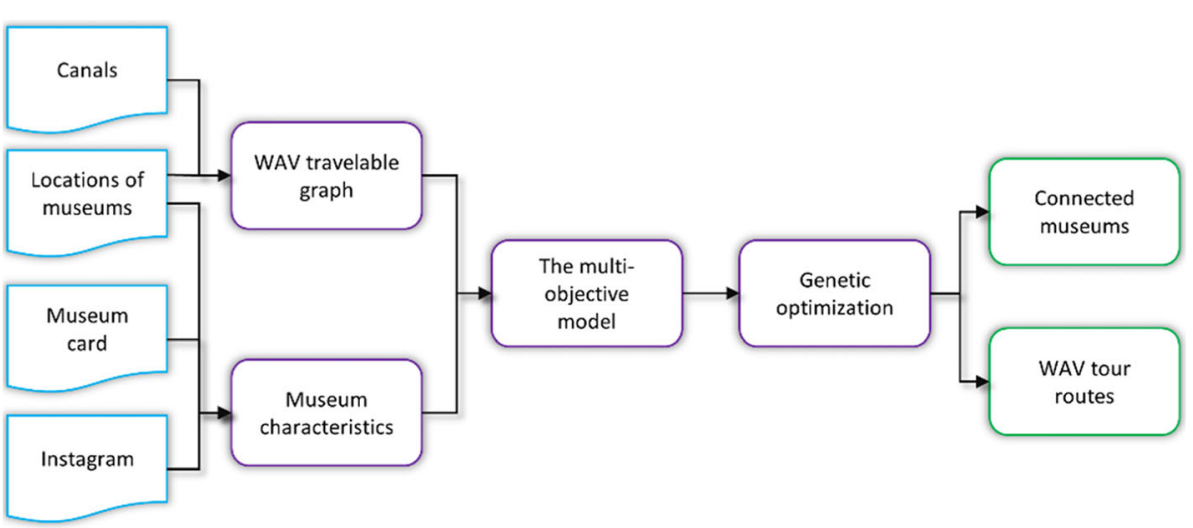

Fig. 3 Workflow to design WAV routes for museums

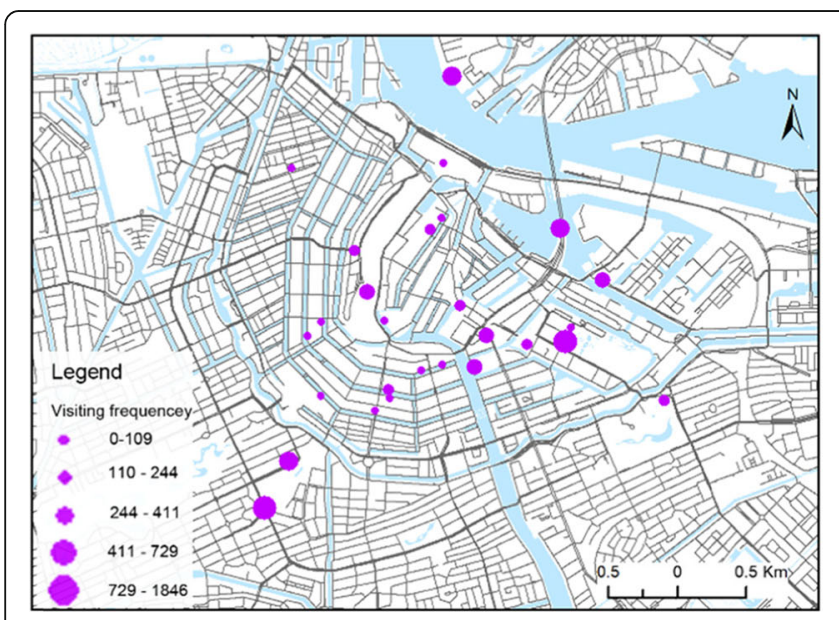

(a)

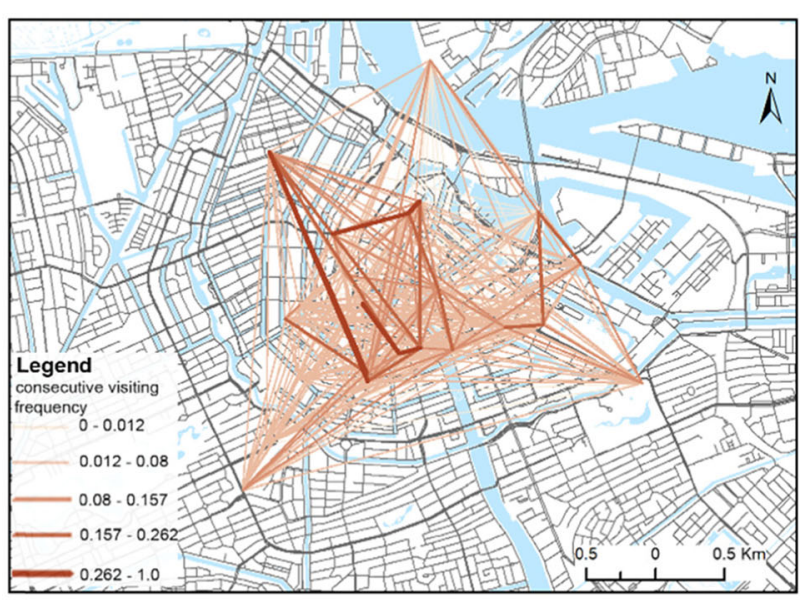

(b)

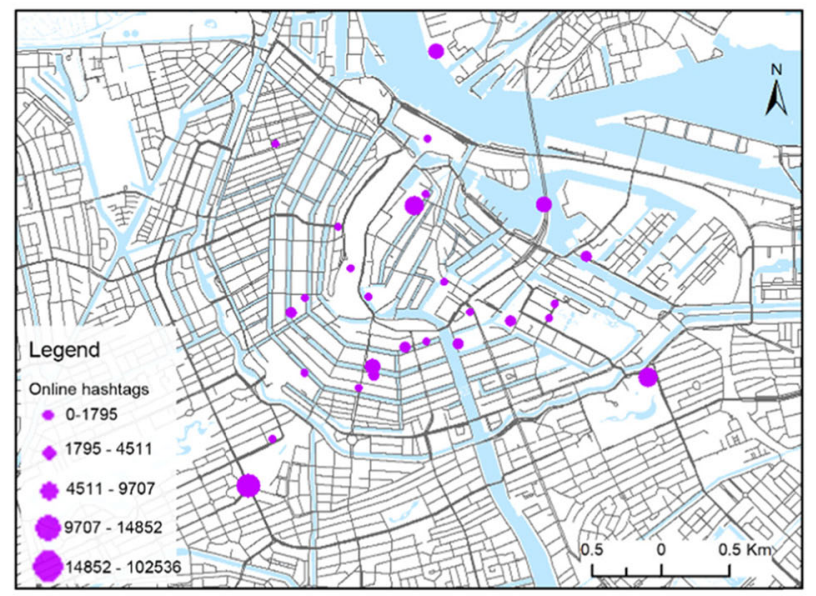

(c)

Fig. 4 Characteristics of museums in Amsterdam's Central area. a Offline popularity of museums. b Visitation frequency of a pair of museums; $\mathbf{c}$ online presence of museums 
The I Amsterdam City Card, on the other hand, is a hospitality product launched by Amsterdam Marketing targeting international visitors. The I Amsterdam City Card database keeps track of which museums a visitor has visited during his or her stay. The I Amsterdam City Card users visit on average of 5.1 museums and attractions during their stay. Of these, 3.6 museums and attractions are OAM members. A boat trip and a visit to the Van Gogh Museum are by far the most popular activities, accounting for $87 \%$ and $73 \%$ respectively among the total cardholders.

Using the I Amsterdam City Card statistics [3], we measure the offline popularity of museums by tabulating the number of museum visits in the last 5 years. Figure 4a visualizes museum visitations in Amsterdam city center, which demonstrates uneven offline popularity of museums.

On the other hand, the I Amsterdam City Card data reveals that many tourists visit more than one museum. Consequently, the high frequency of museum pairs $i$ and $j, q_{i j}$, are expected in the optimal WAV route. Figure $4 \mathrm{~b}$ shows the visitation frequency of going from one museum to another. It illustrates that several pairs of museum exhibit relatively high frequency, which highlights the importance of museum visitation sequence in the following WAV route design.

\subsubsection{Online presence of museums}

We have scraped Instagram data of all Amsterdam's museums to evaluate their online presence. We use the total number of Instagram hashtags for the museums as the indicator for online popularity. Figure $4 \mathrm{c}$ shows the results of online popularity. Comparing to Fig. 4a, this metric shows that some museums with active online presence do not have high offline popularity, such as the Tropen Museum and the Oude Kerk.

\subsection{Multiple objective optimization model}

The characteristics outlined in the previous section demonstrate the uneven online and offline museum visitation preferences. Here, we present a multi-objective optimization approach to automatically optimize museum tour routes with on-demand WAVs in Amsterdam. Generally, four aspects will be considered:

(1) Visitation frequency. Using the data from the Amsterdam Museum Monitor 2016 report, the visitation numbers of each museum in the last 5 years is collected to denote offline popularity. The visitation frequency of museum $i$ is denoted as $O_{i}^{1}$.

(2) Museum visitation patterns. The visitors may prefer to visit two or more museums in a day. The I Amsterdam City Card data contain the consecutive visitation sequence of museums. The count of visiting museum $j$ after another museum $i, q_{i j}$, is calculated to represent the preference of chain visits.

(3) Online popularity of museums. The cumulated Instagram hashtags of the museums are calculated to denote the online popularity of the museum $i$, $\mathrm{O}_{i}^{2}$.

(4) Travel cost. Longer distance WAV routes require more time to transfer visitors between museums, thereby reducing the attraction of visiting museums via WAV. Here, we take the travel cost (e.g., travel distance or travel time by WAVs) from the museum $i$ to $j$ as the physical dependence, $c_{i j}$.

To find the best WAV routes, we construct the graph model $\boldsymbol{G}=<N, A>$ to represent the travelable context of WAVs, according to locations of museums and canals. The graph $\boldsymbol{G}$ is comprised of a node set $N$ and an arc set $A$. One node $n$ in the node set $N$ denotes a museum with many features, including ID, position, name, online popularity, and visitation frequency. One $\operatorname{arc} a_{i j}$ in the arc set $\boldsymbol{A}$ denotes a direct travel from the museum $i$ to $j$ associated with the consecutive visitation frequency $\left(q_{i j}\right)$ and the travel cost $\left(c_{i j}\right)$. Basically, one WAV route can be represented by a sequence of museums, $r=\{1,2$, ..., $M$ \}, where $M$ is the count of docking places in a WAV route.

Optimizing WAV routes is to select a subset of museums and traverse them with the given number of WAVs. Considering the above four aspects, the goal is to find the most attractive and efficient WAV routes to serve tourists. One objective is to cover the popular museums. Another is to improve the travel experience of the museum visit. Formally, optimizing WAV routes can be modeled as the WAV routing problem (WAVRP) below:

$$
\begin{aligned}
F(S)= & \sum_{i=1}^{N}\left(w_{1} O_{i}^{1}+w_{2} O_{i}^{2}\right) \sum_{j, k} x_{i j k} \\
& +\sum_{k} x_{i j k}\left(w_{3} q_{i, j}-w_{4} c_{i, j}\right)
\end{aligned}
$$

s.t.,

$$
\begin{aligned}
& \sum_{i, k} x_{i j k} \leq L, i \in\{1,2, \ldots, N\} \\
& \sum_{j, k} x_{i j k} \leq L, j \in\{1,2, \ldots, N\} \\
& 2 \sum_{i, j} x_{i j k}-\sum_{h, j} x_{h i k} x_{i j k} \leq M, k \in K \\
& \sum_{l=1}^{4} w_{l}=1, w_{l} \in[0,1] \\
& x_{i j k} \in\{0,1\}, i, j \in\{1,2, \ldots, N\}, k \in\{1,2, \ldots, K\}
\end{aligned}
$$

Where $x_{i j k}$ is a $0-1$ variable indicates there is a segment from the museum $i$ to $j$ in the route $k . K$ is the 
route set. In other words, if the route $k$ contains the consecutive travel from $i$ to $j, x_{i j k}=1$; otherwise, $x_{i j k}=0 . O_{i}^{1}$ and $O_{i}^{2}$ are the online popularity and visitation frequency of museum, $i$, respectively. $q_{i, j}$ and $c_{i, j}$ are the consecutive visitation frequency and travel cost from the museum $i$ to the museum $j$ in the route $k . w_{1} \sim w_{4}$ are the weighting parameters for the objectives. The constraints (2) and (3) require that each museum can be visited no more than $L$ times in WAV routes. Equation (4) limits total museum count in a route no more than $M$. Equation (5) requires the objective weight to be within the range $[0,1]$. Note that the WAVRP is different from the VRP as not all museums are required to be visited.

\subsection{The solving method}

The presented WAVRP is difficult to solve due to the inherent museum selection and museum traverse. The heuristic algorithm is a promising method for complex optimization problems, i.e., local search, simulated annealing, ant colony optimization, genetic algorithm (GA), etc. GA evolves to globally optimal solutions for complex optimization problems by simulating natural behavior (Mitchell, M [40]). Because of its easy-toimplement characteristics and its good performance, GA has been successfully applied to many complex optimization problems, such as locating charging stations [6], designing personalized tour routes [38], and providing route recommendation [41].

We employ the GA to optimize the WAV routes. GA contains several components: genome coding, population generation, fitness function, and selection, crossover, mutation, and stopping criteria ( $\mathrm{Tu}$ et al [6]). For the WAV route optimization, we use the integer representation to encode the museums in a route as a gene. The order represents the traverse sequence. All routes are represented by a chromosome. The objective function (Eq. (1)) serves as the fitness function of each individual. An initial population of WAV routes is generated by randomly sorting museums. At each generation, the roulette wheel rule is enforced on the selection. Crossover is accomplished by the 2-point crossover operator [42]. The mutation is employed at some random positions. Simulated evolution is repeated until the maximum number of iterations $N_{\max }^{1}$ has been reached or the objective (Eq. (1)) has not been improved over a fixed number of iterations $N_{\max }^{2}$. Finally, the optimal results are reported, and corresponding WAV routes are decoded. Details of the aforementioned four parameters are obtained.

Before optimizing WAV routes, the parameters of the genetic algorithm, such as the population size $p$, the selection rate $\alpha \alpha$, the mutation rate $\beta, N_{\max }^{1}$, and $N_{\max }^{2}$ $\mathrm{N}_{\max }^{1}$, are established after intensive experiments using the parameter tuning method of Coy et al. [43].

\section{Experiment and results}

Using urban data of Amsterdam, we built the multiobjective model and solved it with the GA. The canal network is firstly digitized to the travelable graph from the high-resolution satellite image for the WAV route optimization. In total, the graph contains 275 nodes and 357 edges. Experiments were set up to assess the performance of the presented model and evaluate the results. The resulting WAV routes were mapped and compared against current land transportation.

\subsection{Experiment set-up}

After investigating the museum visitation patterns in Amsterdam, two scenarios are set up as below.

- Scenario A: WAV routes depart from Amsterdam Central Station. As many foreign and domestic visitors first arrive in Amsterdam at the Central Station, we assume all museum WAVs begin their tours here in this scenario.

- Scenario B: WAV can depart from any museum. The first museum of one WAV route can be anywhere along the canal, for example, the nearest dock to the Van Gogh Museum.

According to Museumkaart usage statistics, one visitor generally explores 2 to 4 museums in one day [3]. Hence, we set the number of museums in a WAV route, $L$ to 4 . The total visitation of one museum, $M$, is set to 2 . To demonstrate the utility of WAVs, we varied the number of WAV routes, $K$, from 1 to 4 . In terms of the objective weighting, we set $w_{1} \sim w_{4}$ to 0.25 , in other words, the equal weight. For the details of all scenarios, see Tables 1 and 2 below. Here, we set the museum number of WAV route in Scenario A to 3 as the Central Station is regarded as a virtual museum while Scenario B to 4.

\subsection{WAV routes}

After building the WAVRP model and solving it with GA, we obtained the optimal routes for museum tours by WAV and the corresponding objectives. Table 1 reports the objective of Scenario A. Figure 5 displays the corresponding WAV routes, each departs from Amsterdam Central Station and traverses 3 museums. It demonstrates the best WAV route of A1 (Fig. 5a) departs from the Amsterdam Central Station, goes to the Diamant Museum and the Stedelijk Museum, and ends at the Van Gogh Museum. Museums in this route has a total of 164,746 Instagram hashtags and 3,142,272 total visitors per year. The total length is $3885 \mathrm{~m}$. This route is representative of current museum visitation preference pattern, with the consecutive visitation frequency of 0.21 . These high online and offline popularity and 
Table 1 Objective of WAV routes departing from Amsterdam Central Station

\begin{tabular}{|c|c|c|c|c|c|c|}
\hline \multirow[t]{2}{*}{ Scenario } & \multirow{2}{*}{$\begin{array}{l}\text { Museum } \\
\text { per } \\
\text { route } M\end{array}$} & \multirow{2}{*}{$\begin{array}{l}\text { Route } \\
\text { count } \\
K\end{array}$} & \multicolumn{4}{|l|}{ Objectives of WAVs } \\
\hline & & & Online popularity $O^{2}$ & Offline popularity $\mathrm{O}^{1}$ & Consecutive frequency & Travel distance (/meter \\
\hline $\bar{A} 1$ & 3 & 1 & 164,746 & $3,142,272$ & 0.21 & 3885 \\
\hline $\mathrm{A} 2$ & 3 & 2 & 177,649 & $5,822,581$ & 0.48 & 7756 \\
\hline A3 & 3 & 3 & 192,989 & $6,422,648$ & 0.97 & 9923 \\
\hline A4 & 3 & 4 & 202,644 & 7310,990 & 1.30 & 13,413 \\
\hline
\end{tabular}

visitation frequency verify the effectiveness of the presented model and solution method.

When the number of WAV routes increases, the online popularity and visitation frequency of covered museums increase as Table 1. reports. As the number of WAV routes increases to 4 , total online popularity rises to 202,644 hashtags and offline visitation frequency climbs to 7310,990 visitors per year. The consecutive frequency along the designed WAV routes rises to 1.30 . Meanwhile, the total route distance rises to $13,913 \mathrm{~m}$. Scenarios A1-A4 further demonstrate that the WAV routes take the Amsterdam Central Station as the hub. By putting more WAVs into usage, the routes gradually spread to the Amsterdam core area and form a star topology structure. From Scenarios A1 to A4, new WAV routes appear in the east and the center. The presented model balances between coverage of highly popular museums and low travel distance.

The results of Scenario B departing from any museum are reported in Table 2. Figure 6 displays the corresponding routes. It demonstrates that the best WAV routes which improve museum experience in this Scenario will link $4 \mathrm{mu}-$ seums. The reported route (Fig. 6a) has a total of 164,796 hashtags, 4,490,789 visitors per year, and $3454 \mathrm{~m}$ of total travel distance, outperforming those of A1. This route corresponds highly to current museum visitation sequence and pattern, with a consecutive frequency of 0.28 . By removing the requirement of the departure position, the indicators of the WAV route have further improved. When WAV routes increase, multiple routes are interconnected at one museum. For example, taking the B3 as an example, both route r1 and r2 contain the Van Gogh Museum. The routes in Fig. 6c and $\mathrm{d}$ further illustrate that, when more WAVs are used, the routes will be connected and produce a WAV network.
By comparing the corresponding scenarios in $\mathrm{A}$ and $\mathrm{B}$, it can be observed that without the departure constraint, WAV routes in Scenario B cover museums with higher online popularity, visitation frequency and consecutive frequency but shorter distance. For example, WAV routes in B4 cover 11 museums with a total 315,003 hashtags, 9,590,475 annual visitors, and a consecutive frequency of 1.24, while A4 cover 12 museums with a total of 202,644 hashtags, 7310,990 annual visitors, and consecutive frequency of 1.30. Figure 6a-d further shows that, without the departure constraint, WAV routes will cover more museums at the center of Amsterdam.

\subsection{Comparison to land transportation}

Further evaluating the viability of WAV-based tour routes, we compared the WAV routes with current public transit routes using subway and buses. Three travel indicators, including total travel distance, travel time, and necessary walking distance were compared. Note that the travel distance considers both the total distance traveling by boat and any additional distance required for walking. In terms of travel time, we added a dummy of $30 \mathrm{~s}$ for each canal intersection to the total travel time by WAV to account for possible delays at these intersections. According to transportation regulations in Amsterdam, WAV speed in Amsterdam's Central area is restricted to $6 \mathrm{~km} / \mathrm{hr}$. to ensure safety and reduce traffic noises.

These results show that using WAVs as a mode of transport to visit museums in Amsterdam is a viable alternative to traditional land transportation. Results show that the trade-off of using WAVs as opposed to public transit concerns travel time and total distance. The total travel distance of WAV routes is significantly less than

Table 2 Objective of WAV routes with free departure

\begin{tabular}{|c|c|c|c|c|c|c|}
\hline \multirow[t]{2}{*}{ Scenario } & \multirow{2}{*}{$\begin{array}{l}\text { Museum } \\
\text { per } \\
\text { route } M\end{array}$} & \multirow{2}{*}{$\begin{array}{l}\text { Route } \\
\text { count } \\
K\end{array}$} & \multicolumn{4}{|l|}{ Objectives of WAVs } \\
\hline & & & Online popularity $O^{2}$ & Offline popularity $O^{1}$ & Consecutive frequency & Travel distance (/meter) \\
\hline B1 & 4 & 1 & 164,796 & $4,490,789$ & 0.28 & 3454 \\
\hline B2 & 4 & 2 & 172,493 & $5,139,192$ & 0.66 & 3167 \\
\hline B3 & 4 & 3 & 292,939 & $9,155,177$ & 0.98 & 5658 \\
\hline B4 & 4 & 4 & 315,003 & $9,590,475$ & 1.23 & 12,925 \\
\hline
\end{tabular}




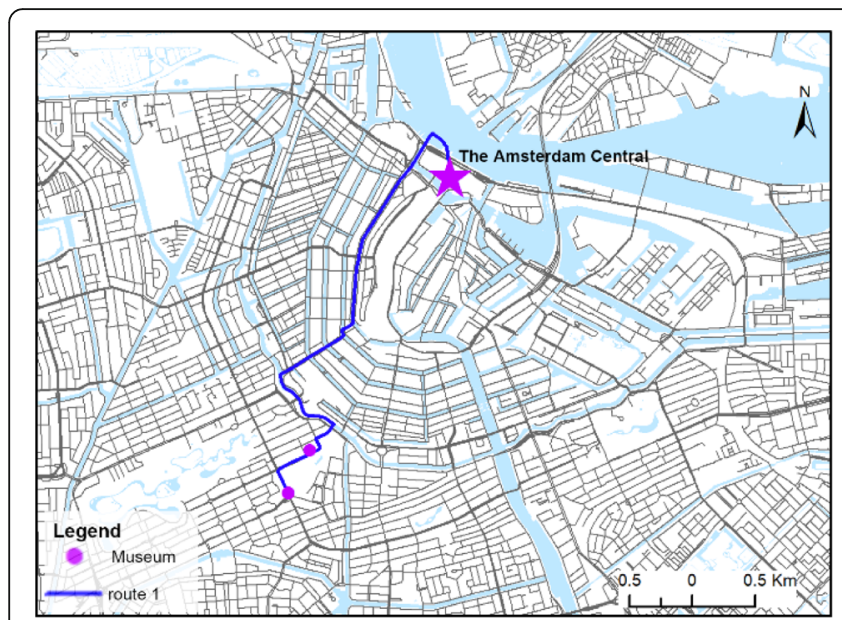

(a) A1

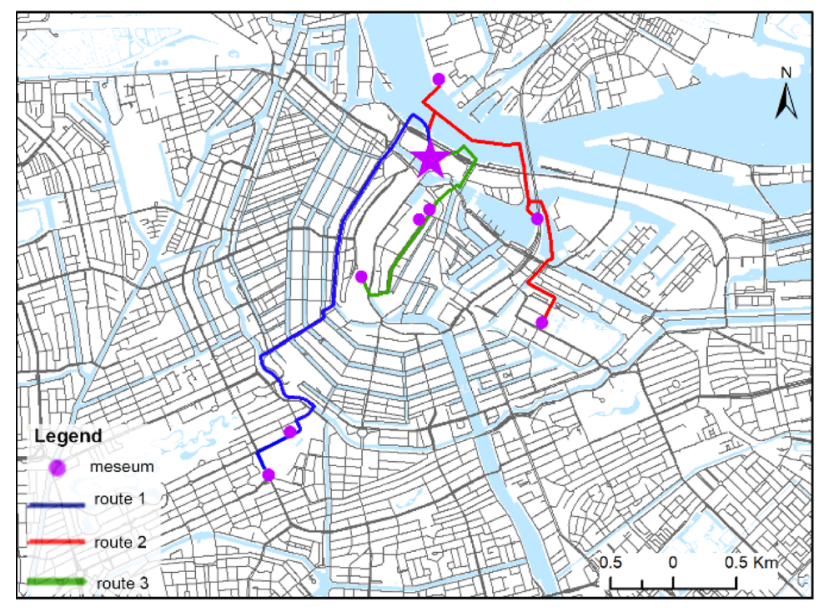

(c) A3

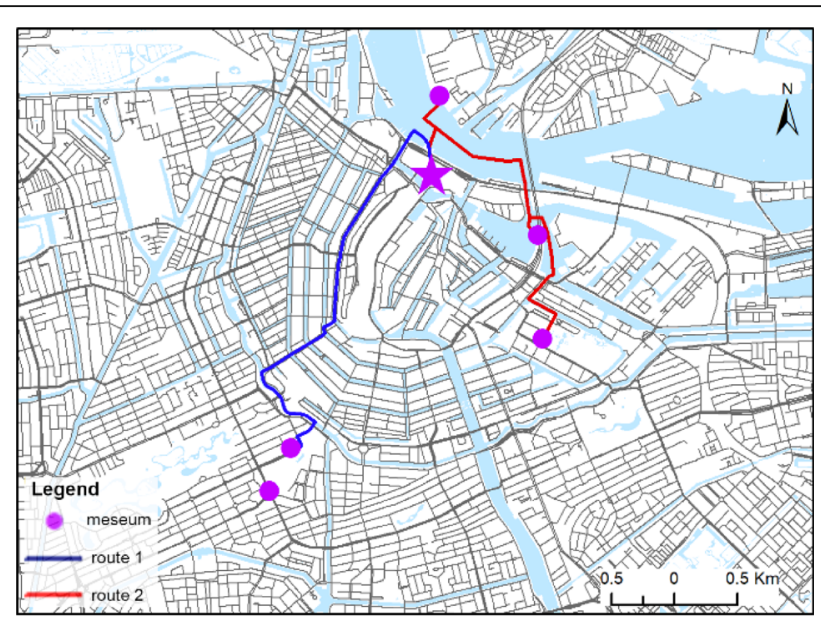

(b) A2

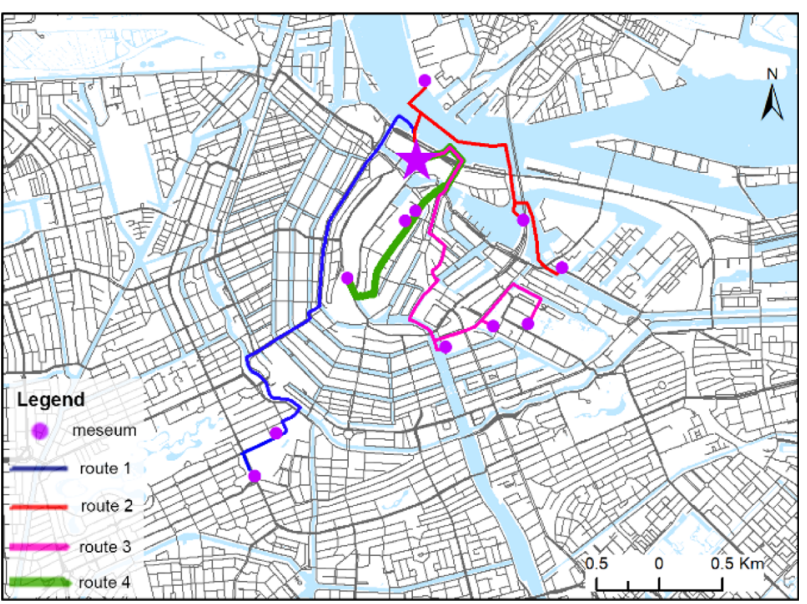

(d) A4

Fig. 5 WAV routes for the museums in Amsterdam

that of land transportation. Traveling by WAVs is slower than using public transit by an average of $3.3 \mathrm{~min}$, due to Amsterdam's boat speed limitation. In the future, this speed limitation will likely increase as more sensors are equipped to detect the surroundings to improve travel safety. On the other hand, optimized WAV route reduces walking time significantly by taking advantage of the well-connected canals. In our two case studies, the total walking distance in the eight scenarios for WAV routes is $7316 \mathrm{~m}$, whereas the walking distance for traveling via public transit is $25,746 \mathrm{~m}$. For museum tourists, this could be a significant incentive to use WAVs when public transit options are less ideal (Table 3).

\subsection{Acceptance of WAVs}

To further assess our hypothesis, we conducted an online survey using Amazon Mechanical Turk to evaluate users' attitude towards different modes of transport for museum visits and their various tradeoffs. We ask users to rate three case scenarios out of a score of 5: (1) using traditional land public transit and arriving $10-15 \mathrm{~min}$ earlier; (2) using a traditional tour boat in the canal and allowing the tourist to enjoy some scenery along the canals; (3) allowing the tourist to order a WAV for a customized experience and enjoying the scenery along the way.

A total of 268 responses were received (Table 4), 182 of which were from respondents who are from or have been to Amsterdam. We consider these to be useable samples. Among them, 174 respondents are frequent museum visitors; 171 reported their preferences to use WAVs as an alternative mode of transport. The results further show that WAV-based museum visitation integrating innovative technology and historical museum visit is the most attractive case for tourists. Case 3 by WAV has the highest ranking, with an average score of 


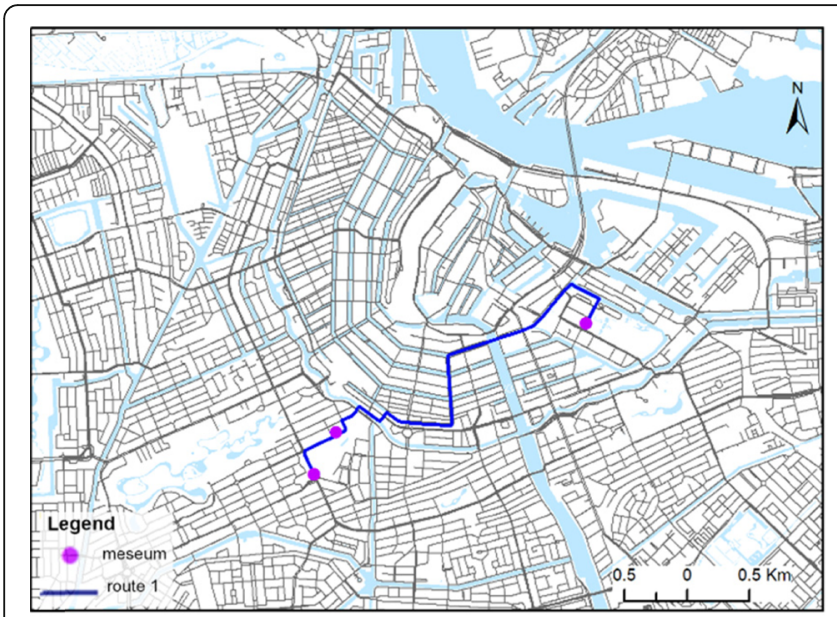

(a) B1

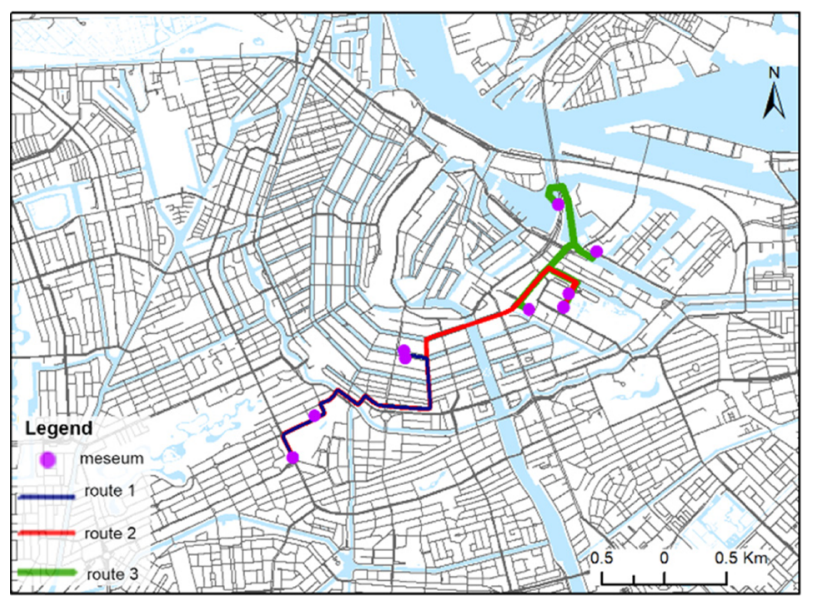

(c) B3

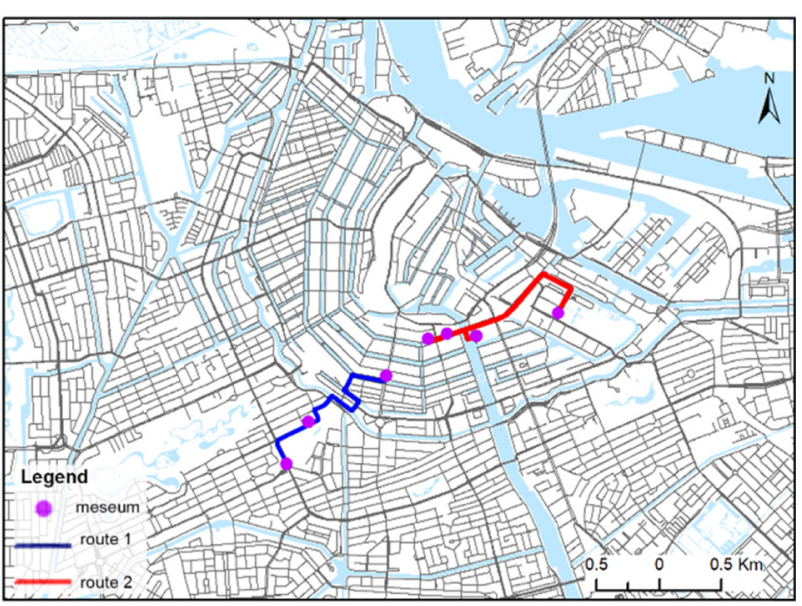

(b) B2

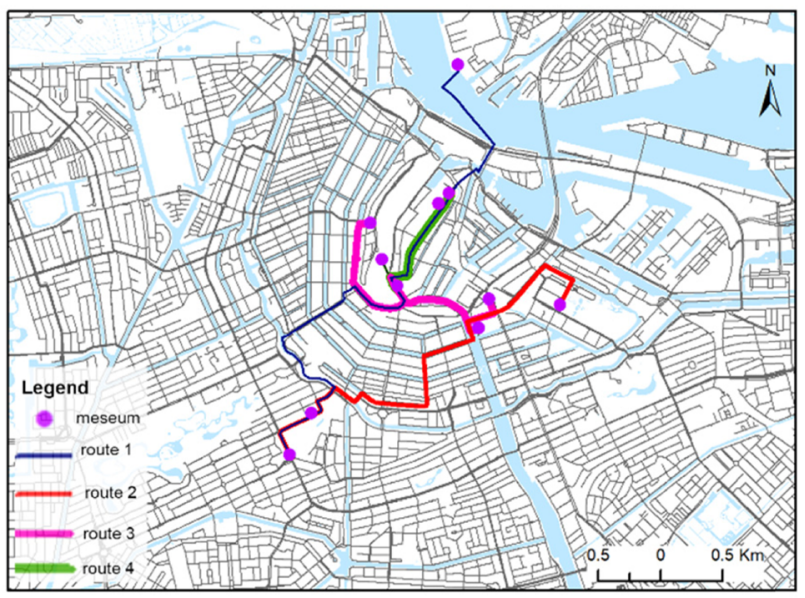

(d) B4

Fig. 6 WAV routes with free departure

Table 3 Comparison of WAV and public transit

\begin{tabular}{|c|c|c|c|c|c|c|}
\hline \multirow[t]{2}{*}{ Scenario } & \multicolumn{3}{|l|}{ WAV } & \multicolumn{3}{|l|}{ Land transportation } \\
\hline & $\begin{array}{l}\text { Total travel distance } \\
\text { (meter) }\end{array}$ & $\begin{array}{l}\text { Total travel time } \\
\text { (/minutes) }\end{array}$ & $\begin{array}{l}\text { Total Walking } \\
\text { Distance }(\mathrm{m})\end{array}$ & $\begin{array}{l}\text { Total travel distance } \\
\text { (meter) }\end{array}$ & $\begin{array}{l}\text { Total travel time } \\
\text { (minutes) }\end{array}$ & $\begin{array}{l}\text { Total Walking } \\
\text { Distance }(\mathrm{m})\end{array}$ \\
\hline $\bar{A} 1$ & 3885 & 39 & 551 & 4821 & 22 & 491 \\
\hline$A 2$ & 7756 & 78 & 1022 & 17,441 & 79 & 2041 \\
\hline A3 & 9923 & 99 & 1362 & 18,861 & 94 & 3461 \\
\hline A4 & 13,413 & 134 & 1445 & 22,921 & 121 & 5641 \\
\hline B1 & 3454 & 35 & 610 & 3532 & 26 & 1242 \\
\hline B2 & 3167 & 32 & 615 & 3191 & 27 & 1732 \\
\hline B3 & 5658 & 57 & 741 & 7910 & 67 & 4380 \\
\hline B4 & 12,925 & 129 & 970 & 12,248 & 101 & 6758 \\
\hline Total & 60,181 & 603 & 7316 & 90,945 & 537 & 25,746 \\
\hline
\end{tabular}


Table 4 Results of the museum visits survey

\begin{tabular}{ll}
\hline Total number of responses & $\mathbf{2 6 8}$ \\
\hline Total number of respondents from or have been to Amsterdam & 182 \\
Number of respondents who like to visit museums & 174 \\
Number of respondents who visits museums when traveling to new cities & 171 \\
Average number of museums visited in one day & 2.11 \\
Number of respondents who are open to using WAV & 168 \\
Case 1 (road transportation) average score $\left(\mu_{1}\right)$ & 2.91 \\
Case 1 (road transportation) standard deviation $\left(\sigma_{1}\right)$ & 1.106 \\
Case 2 (traditional boat) average score $\left(\mu_{2}\right)$ & 3.29 \\
Case 2 (traditional boat) standard deviation $\left(\sigma_{2}\right)$ & 1.178 \\
Case 3 (WAV) average score $\left(\mu_{3}\right)$ & 3.51 \\
Case 3 (WAV) standard deviation $\left(\sigma_{3}\right)$ & 1.121 \\
\hline
\end{tabular}

3.51, followed by case 2 with an average score of 3.29, and case 1 with an average score of 2.91 .

Hypothesis 1: Respondents prefers the boat more than land transportation for museum visitation in Amsterdam.

As the difference of average reported score for the case by road transportation and traditional boat is 0.38 (= 3.29-2.91). The paired-samples T Test $(4.739>1.960)$ illustrate that the difference between travel by road transportation and by boat is significantly more than 0 , under the confidential level $p=0.05$. The hypothesis is accepted. In other words, the result verifies the respondents prefer the boat for museum visitation.

Hypothesis 2: Tourists prefer the WAV more than the boat for museum visitation in Amsterdam.

Similarly, the difference of average reported score of case 3 and case 2 is $0.22(=3.52-3.29)$. The pairedsamples $\mathrm{T}$ Test $(2.823>1.960)$ demonstrate this difference is significantly more than 0 , under the confidential level $p=0.05$. Therefore, hypothesis 2 is accepted. The result verifies the respondents statistically prefer the WAV for museum visitation.

Above all, these findings verify the acceptance of WAV for museum tourism. Although waterborne travel entails longer travel time, the beautiful canal scenery and user tendency to experience a novel transit mode can compensate for the longer travel time. Furthermore, a customizable transit experience with flexible departure times using WAVs are more preferred than the use of traditional tour boats, which requires more standardized operations and traveling with larger groups of people. This survey confirms the viability of WAVs for museum visitation.

\section{Discussion and conclusion}

With the development of ICT and IoT, AI has great impacts on tourism, such as understanding visitor behavior $[18,44]$, suggesting personalized tourism route recommendation (Zheng and Liao [38]), and enhancing tourism marketing [23]. Although embracing autonomous vehicle in contemporary urban tourism still faces great challenges, the technology is hailed as an innovation that will drastically change urban mobility and personal travel behaviors [30]. Embracing such trends, this study introduces WAVs to provide alternative transportation choices for museum visitors in Amsterdam.

Taking advantage of Amsterdam's canal networks, we present an innovative WAV-based museum tourism. Using historical museum visitation data and social media data, we consider the online and offline popularity of museums, the sequential visitation of museums and travel cost to be relevant factors influencing museum visitation. A multi-objective model is proposed and solved to find optimal WAV routes. The experiment then reports that, although restricted by the low boat speed of $6 \mathrm{~km} / \mathrm{h}$ outlined by law, traveling to museums via WAV is still comparable to using current public land transportation in terms of efficiency and convenience. Supported by empirical data, the study demonstrates that the presented WAV-based museum visitation is of good performance and well acceptance.

The presented approach connects historical tourist destinations with emerging urban mobility technologies by integrating cultural museum visitation and use of WAVs in Amsterdam. Considering the popularity of current canal boat tours, new tourist packages that combine museum visitation and WAV tour will effectively boost the economic benefits of tourist activities and attract a wider audience for cultural participation. The combination of optimized museum visitation and boat tour suggests future collaboration between different museums and WAV operators, which could lead to the potential implementation of a new tourist package in future tourism measures.

Amsterdam faces the challenge of uneven distribution of tourists. While the top five museums receive the 
highest numbers of visitors, small- and medium-sized museums experience declines overtime. Around $68 \%$ of government subsidies go to museums attracting over 100 thousand visitors, whereas museums with less than 10,000 visitors receive less than $3 \%$ of the total subsidies [45]. Not only does this raise economic concerns, unbalanced tourist distribution causes unwanted congestions. Such congestion issues caused by concentrated tourism is a problem faced by many cities around the world [46]. This study suggests a potential solution to these problems. As a positive side effect, while each optimal route always includes one or two top museums, it manages to pick up smaller and lesser known museums along the way and redistributes tourists to these destinations, allowing visitors to gain greater exposure to a diverse cultural landscape. With the future possibility of combining WAV routes with tourist packages, it is possible to promote smaller museums while balancing unwanted tourist traffic using WAV, helping the city solve both economic and urban congestion challenges. In the future, our model could connect with real-time crowdlevel data at different museums and generate routes which avoid long waiting times for the visitors. The ondemand nature of our proposal allows it to be an effective crowd management tool. Further research is also needed in the operation of WAV from a fleet perspective. The design of Roboat allows for modular combination which forms larger platforms. This flexibility allows the WAV system to respond to changing tourist volumes during different times of the day, week, and year, as well as the ability to host larger cultural events associated with museum visitation. The proposed method and recommendation system can be well incorporated into the IoT smart city infrastructure. Route data collected over time will provide valuable insights to tourist preference and travel behaviors, allowing the system to improve and optimize over time.

The contributions of this study lie in the following aspects: (1) the innovative application of WAVs is introduced to museum tourism. According to our knowledge, it is the first study in this domain; (2) A novel multiobjective optimization approach integrating multi-source urban data is proposed to find the WAV routes, taking advantages of the popular canal boat tour and Amsterdam's rich museum culture; (3) implications for novel tourism management methods such as crowd management and development of new tourist packages, which allows for redistribution of tourists, reduction of urban congestions, and increased exposure and economic benefits to lesser-known destinations.

\section{Acknowledgements}

The authors thank the AMS Institute, RATP, Dover Corporation, Teck Resources, Lab Campus, Anas S.p.A., Ford, Brose, ENEL Foundation, Università di Pisa, KTH Royal Institute of Technology, Institut Teknologi Bandung, UTEC -
Universidad de Ingeniería y Tecnología, Politecnico di Torino, Fraunhofer Institute, SMART - Singapore-MIT Alliance for Research and Technology, Curitiba, Laval, Munich, Stockholm, and Amsterdam.

\section{About the Authors}

Helena Hang Rong is a researcher at Senseable City Lab, Massachusetts Institute of Technology, where she is responsible for leading and developing Augmented Reality platform on IOS devices for public engagement exhibition for the Roboat project, the first fleet of autonomous boats in Amsterdam, and researching into travel optimization to cultural destinations in the city with autonomous waterborne vehicles. She is currently doing a $\mathrm{PhD}$ at Columbia University.

Wei Tu is senior associate research fellow at Guangdong Key of Urban Informatics, Shenzhen University, China. He is a research fellow at the Senseable City Lab, Massachusetts Institute of Technology. His research interests focus on the urban informatics, including data-driven human activity-mobility, multi-source geospatial data fusion, and smart city applications.

Fábio Duarte is a research scientist at the Senseable City Lab, the Massachusetts Institute of Technology, and professor at Pontificia Universidade Catolica do Parana, Curitiba, Brazil. Duarte is consultant in planning and transportation for the World Bank. His most book is Unplugging the City (Routledge, 2018).

Carlo Ratti is is a professor of the practice and the director of the Senseable City Lab at the Massachusetts Institute of Technology, and co-founder and principal of Carlo Ratti Associati, a global innovation and design firm. Ratti's most recent book is The City of Tomorrow (Yale Press, 2017). He has been included in Blueprint's '25 People Who Will Change the World of Design' and in Wired's 'Smart List: 50 People Who Will Change the World'. He is currently serving as Chair of the World Economic Forum Global Agenda Council on Future Cities.

\begin{abstract}
Authors' contributions
H.H. Rong proposed the main idea, conducted the data analysis, designed experiment and analyzed results. W. Tu developed the waterborne autonomous vehicle route optimization method and analyzed results. F. Duarte proposed the main idea, discussed and wrote some parts of the manuscript. C. Ratti led the project and designed the experiment. The author(s) read and approved the final manuscript.
\end{abstract}

\section{Funding}

This work was jointly supported by China Scholarship Council [grant number 201708440434].

\section{Availability of data and materials}

The datasets used and/or analyzed during the current study are available from the corresponding author on reasonable request.

\section{Competing interests}

The authors declare that they have no competing interests.

\section{Author details}

${ }^{1}$ Senseable City Lab, Massachusetts Institute of Technology, MIT 9-216, 77 Massachusetts Avenue, Cambridge, MA 02139, USA. ${ }^{2}$ Graduate School of Architecture, Planning and Preservation at Columbia University in the City of New York, New York City, NY 10027, USA. ${ }^{3}$ Shenzhen Key Laboratory of Spatial Information Smart Sensing, School of Architecture and Urban Planning, Shenzhen University, Shenzhen 518060, China. ${ }^{4}$ Pontfícia Universidade Católica do Paraná, Curitiba, Brazil.

Received: 2 June 2020 Accepted: 17 November 2020

Published online: 27 November 2020

\section{References}

1. Rawding, C. (2000). Tourism in Amsterdam: marketing and reality. Geography, 85, 167-172.

2. Dai, T. C., Hein, C., \& Zhang, T. (2019). Understanding how Amsterdam City tourism marketing addresses cruise tourists' motivations regarding culture. Tourism Management Perspectives, 29, 157-165. 
3. AMMR. (2016). Amsterdam museum monitor 2016 report. http:// codeculturelediversiteit.com/wp-content/uploads/2017/02/ Museummonitor-2016-final-version.pdf [Accessed 30 Jan 2019]

4. Pinkster, F. M., \& Boterman, W. R. J. (2017). When the spell is broken: gentrification, urban tourism and privileged discontent in the Amsterdam canal district. Cultural Geography, 24(3), 457-472.

5. Batty, M. (2013). Big data, smart cities and city planning. Dialogues in Human Geography, 3(3), 274-279.

6. Tu, W., Li, Q., Fang, Z., Shaw, S.-L., Zhou, B., \& Chang, X. (2016). Optimizing the locations of electric taxi charging stations: a spatial-temporal demand coverage approach. Transportation Research Part C: Emerging Technologies, 65, 172-189.

7. Tu, W., Cao, J., Yue, Y., Shaw, S.-L., Zhou, M., Wang, Z., ... Li, Q. (2017a). Coupling mobile phone and social media data: a new approach to understanding urban functions and diurnal patterns. International Journal of Geographical Information Science, 31(12), 2331-2358.

8. Tu, W., LI, Q. Q., Li, Q. P., Zhu, J. S., Zhou, B. D., \& Chen, B. Y. (2017b). A spatial parallel heuristic approach for solving very large-scale vehicle routing problems. Transactions in GIS, 21(6), 1130-1147.

9. Wu, N., \& Silva, E. (2010). Artificial intelligence solutions for urban land dynamics: a review. Journal of Planning Literature, 24(3), 246-265.

10. Kellerman, A. (2018). Automated and autonomous spatial motilities. Cheltenham: Edward Elgar.

11. Lu, M. J., Taiebat, M., Xu, M., \& Hsu, S. C. (2018). Multi-agent spatial simulation of autonomous taxis for urban commute: travel economics and environmental impacts. Journal of Urban Planning and Development, 144, 12.

12. Duarte, F., \& Ratti, C. (2018). The impact of autonomous vehicles on cities: a review. Journal of Urban Technology, 25(4), 3-18.

13. Porter, L. S., John, L., Crystal, C., Harris, C., Fishman, J., Kent, E., ... Jack, S. (2018). The autonomous vehicle revolution: implications for planning. Planning Theory \& Practice, 19(5), 753-778.

14. Buhalis, D., \& Law, R. (2008). Strategic use of information technologies in the tourism industry. Tourism Management, 19(5), 409-421.

15. Larsen, J., Urry, J., \& Axhausen, K. W. (2007). Networks and tourism - mobile social life. Annals of Tourist Research, 34, 244-262.

16. Lund, N., Cohen, S., \& Scarles, C. (2017). The power of social media storytelling in destination branding. Journal of Destination Marketing \& Management, 8, 271-280

17. Xiang, Z., Du, Q. Z., Ma, Y. F., \& Fan, W. G. (2017). A comparative analysis of major online review platforms: implications for social media analytics in hospitality and tourism. Tourism Management, 58, 51-65.

18. Vu, H. Q., Li, G., Law, R., \& Ye, B. H. B. (2015). Exploring the travel behaviors of inbound tourists to Hong Kong using geotagged photos. Tourism Management, 46, 222-232.

19. Giglio, S., Bertacchini, F., Bilotta, E., \& Pantano, P. (2019). Using social media to identify tourism attractiveness in six Italian cities. Tourism Management, 72, 306-312.

20. Li, J. J., Xu, L. Z., Tang, L., Wang, S. Y., \& Li, L. (2018). Big data in tourism research: a literature review. Tourism Management, 68, 301-323.

21. Hamouda, M. (2018). Understanding social media advertising effect on consumers' responses: An empirical investigation of tourism advertising on Facebook. Journal of Enterprise Information Management, 31, 426-445.

22. Jansson, A. (2018). Rethinking post-tourism in the age of social media. Annals of Tourism Research, 69, 101-110.

23. Tiago, F., Couto, J., Faria, S., \& Borges-Tiago, T. (2018). Cruise tourism: social media content and network structures. Tourism Review, 73, 433-447.

24. Van der Werff, S., Koopmans, C., \& Boyer, C. (2014). The effects of the Dutch museum pass on museum visits and museum revenues. Amsterdam: Seoeconomisch onderzoek December 2014.

25. Fagnant, D. J., \& Kockelman, K. (2015). Preparing a nation for autonomous vehicles: opportunities, barriers and policy recommendations. Transportation Research Part A: Policy and Practice, 77, 167-181.

26. Hebert, M. H., Thorpe, C. E., \& Stentz, A. (2012). Intelligent unmanned ground vehicles: Autonomous navigation research at Carnegie Mellon. Berlin: Springer Science \& Business Media.

27. Duarte, F. (2019). Self-driving cars: a city perspective. Science robotics, 4, 28. https://doi.org/10.1126/scirobotics.aav9843.

28. Milakis, D., Snelder, M., Van Arem, B., Van Wee, B., \& De Almeida Correia, G. H. (2017a). Development and transport implications of automated vehicles in the Netherlands: Scenarios for 2030 and 2050. European Journal of Transport and Infrastructure Research, 17(1), 63-85.
29. Milakis, D., van Arem, B., \& van Wee, G. (2017b). Policy and society related implications of automated driving: a review of literature and directions for future research. Journal of Intelligent Transportation Systems, 21, 324-348.

30. Millard-Ball, A. (2016). Pedestrians, autonomous vehicles, and cities. Journal of Planning Education and Research, 38(1), 6-12.

31. Greenblatt, J. B., S. Saxena (2015). Autonomous taxis could greatly reduce greenhouse gas emissions of U.S. light-duty vehicles. Nature Climate Change, 6. https://doi.org/10.1038/nclimate2685.

32. Cohen, S., \& Hopkins, D. (2019). Autonomous vehicles and the future of urban tourism. Annals of Tourism Research, 74, 34-42.

33. KMPG International. (2018). Autonomous vehicles readiness index: assessing countries' openness and preparedness for autonomous vehicles. https:// assets.kpmg.com/content/dam/kpmg/nl/pdf/2018/sector/automotive/ autonomous-vehicles-readiness-index.pdf. [Accessed 26 March 2019]

34. Larson, R. C., \& Odoni, A. R. (1981). Urban operations research. Prentice-Hall: MIT Press.

35. Chen, D. (1996). Developing algorithms and software for geometric path planning problems. ACM Computing Surveys, 28(4), 18. https://doi.org/10. 1145/242224.242246.

36. Braekers, K., Ramaekers, K., \& Van Nieuwenhuyse, I. (2016). The vehicle routing problem: state of the art classification and review. Computers \& Industrial Engineering, 99, 300-313.

37. Fang, Z., Li, Q., \& Zhang, X. (2013). A multiobjective model for generating optimal landmark sequences in pedestrian navigation applications. International Journal of Geographical Information Science, 25(5), 785-805.

38. Zheng, W., \& Liao, Z. (2019). Using a heuristic approach to design personalized tour routes for heterogeneous tourist groups. Tourism Management, 72, 313-325.

39. Kamga, C., Conway, A., Singhal, A., \& Yazici, A. (2012). Using advanced technologies to manage airport taxicab operations. Journal of Urban Technology, 19(4), 23-43.

40. Mitchell, M. (1998). An introduction to genetic algorithms. MIT Press.

41. Cardoso, P. J. S., Guerreiro, P., Jo, P., \& Veiga, R. (2018). A route planner supported on recommender systems suggestions: enhancing visits to cultural heritage places. In Proceedings of the 8th International Conference on Software Development and Technologies for Enhancing Accessibility and Fighting Info-exclusion, (pp. 144-151). Thessaloniki: ACM.

42. Prins, C. (2004). A simple and effective evolutionary algorithm for the vehicle routing problem. Computers \& Operations Research, 37(12), 1985-2002.

43. Coy, S. P., Golden, B. L., Runger, G. C., \& Wasil, E. A. (2001). Using experimental design to find effective parameter settings for heuristics. Journal of Heuristics, 7(1), 77-97.

44. East, D., Osborne, P., Kemp, S., \& Woodfine, T. (2017). Combining GPS \& survey data improves understanding of visitor behaviour. Tourism Management, 61, 307-320.

45. Centraal Bureau voor de Statistiek (NL). (2015). Largest Dutch museums are winning the struggle for visitors. https://www.cbs.nl/en-gb/news/2015/16/ largest-dutch-museums-are-winning-the-struggle-for-visitors [Accessed 30 Apr 2019]

46. Saenz de Miera Berglind, O., \& Rosselló, J. (2012). The responsibility of tourism in traffic congestion and hyper-congestion: a case study from Mallorca, Spain. Tourism Management, 33, 466-479.

\section{Publisher's Note}

Springer Nature remains neutral with regard to jurisdictional claims in published maps and institutional affiliations. 